\title{
The contribution of Australia's general practitioners to the COVID-19 vaccine rollout
}

Michael Kidd, Lucas de Toca

VACCINATION is the key to getting to the other side of the COVID-19 pandemic, and Australia's general practitioners (GPs) have played - and continue to play - a very significant role. As Australia becomes one of the most highly vaccinated nations against SARS-CoV-2 infection, ${ }^{1}$ GPs and the members of their teams should be feeling proud of their contributions to protecting the health and wellbeing of all people in this country.

Australia's national COVID-19 vaccine rollout was led by the Australian Government's Operation COVID Shield, in partnership with each state and territory. Right from the outset, it was recognised that general practice would be central to the nation's vaccine program, ${ }^{2}$ which was no surprise given the core role Australian general practice plays in the National Immunisation Program (NIP) including childhood immunisations, immunisations for work and travel, and annual influenza immunisations for the whole population.

Australia's GPs had already demonstrated their dedication and commitment throughout the first year of the COVID-19 pandemic, protecting the people most at-risk of the impact of COVID-19 infection, including the elderly and those with chronic health conditions; assessing and testing people with symptoms; managing people diagnosed with COVID-19; continuing regular healthcare for the entire population through the use of telehealth and in-person consultations; and supporting the mental health needs of their patients at a time of great disruption and distress. ${ }^{3}$

On 24 January 2021, the Australian Government announced the key role planned for the nation's GPs in the
COVID-19 vaccine rollout and called for expressions of interest from accredited general practices. ${ }^{2}$ The Royal Australian College of General Practitioners, along with other national stakeholder organisations, had advocated strongly for a core role for general practice in the national vaccine rollout. ${ }^{4}$ While initially there were expectations that approximately 1000 general practices would express an interest, in the end over 4500 general practices submitted expressions of interest in the first round.

The rollout of COVID-19 vaccines in general practice commenced on 22 March 2021 with the AstraZeneca (Vaxzevria) COVID-19 vaccine. ${ }^{5}$ On 5 July 2021, general practices across the country also commenced delivering the Pfizer BioNTech (Comirnaty) vaccine. ${ }^{6}$ Eventually, after expanding eligibility to all general practices participating in the NIP, over 5600 general practices, in rural, regional and metropolitan locations right across the country, have been participating in the national vaccination program, joining 137 of the GP-led Commonwealth Vaccination Clinics, 169 Aboriginal Community Controlled Health Organisation sites, and over 3400 pharmacies, as well as vaccination centres established by each state and territory government.

Through the vaccine rollout, general practices have administered upwards of 100,000 vaccine doses every weekday, with record days of over 200,000, and some weeks administering more than one million vaccines in total. The majority of COVID-19 vaccines administered in Australia to date have been administered through primary care settings, more than 20 million doses at the time of writing, ${ }^{7}$ with general practice delivering more than $80 \%$ of these doses.
The success of the nation's COVID-19 vaccine program reflects the trust the people of Australia have in their general practices and their GPs. The pandemic has highlighted the fundamental importance of relationship-based healthcare and the value Australians place on having their own GP, their own primary care nurse and their own general practice. Many hesitant members of the population have valued the opportunity to consult with their own GP as part of their decision making about vaccination. This has been a key driver of the uptake of the AstraZeneca vaccine, primarily through GPs, despite changing medical advice and concerns regarding the rare adverse events.

As 2021 draws to a close, the role of Australian general practice in the national COVID-19 vaccine program continues, with members of the population continuing to turn up for their initial two doses of a COVID-19 vaccine, and with booster programs now underway for those who completed their course of vaccination more than six months prior. ${ }^{8}$

During this time of global health emergency, our nation's GPs have stepped up to support their patients and their communities when it most counts, to face the challenges of this pandemic together.

\section{Authors}

Michael Kidd AM, MD, FRACGP, FAHMS, Principal Medical Advisor \& Deputy Chief Medical Officer, Australian Government Department of Health, ACT; Professor of Primary Care Reform, Australian National University, ACT

Lucas de Toca MD, MPH, First Assistant Secretary Australian Government Department of Health, ACT; Honorary Senior Fellow, The University of Melbourne, Vic

\section{References}

1. Holder J. Tracking coronavirus vaccinations around the world. New York, NY: The New York Times, 2021. Available at www.nytimes.com/ interactive/2021/world/covid-vaccinationstracker.html [Accessed 6 November 2021]. 
2. Hunt G. GPs' key role in COVID-19 vaccination rollout [Media release]. Canberra, ACT: DoH,

2021. Available at www.health.gov.au/ministers/ the-hon-greg-hunt-mp/media/gps-key-rolein-covid-19-vaccination-rollout [Accessed 6 November 2021].

3. Kidd MR. Five principles for pandemic preparedness: Lessons from the Australian COVID-19 primary care response. Br J Gen Pract 2020;70(696):316-17. doi: 10.3399/ bjgp20X710765.

4. The Royal Australian College of General Practitioners. General practice COVID-19 vaccine rollout commences. East Melbourne: RACGP, 2021. Available at www.racgp.org.au/ gp-news/media-releases/2021-media-releases/ march-2021/general-practice-covid-19-vaccinerollout-commence [Accessed 6 November 2021].

5. Hunt $\mathrm{G}$. Phase 1B COVID-19 vaccination rollout begins [Media release]. Canberra, ACT: DoH, 2021. Available at www.health.gov.au/ministers/ the-hon-greg-hunt- $\mathrm{mp} / \mathrm{media} /$ phase-1bcovid-19-vaccination-rollout-begins [Accessed 6 November 2021].

6. Hunt G. Major step in COVID-19 vaccine rollout [Media release]. Canberra, ACT: DoH, 2021. Available at www.health.gov.au/ministers/ the-hon-greg-hunt-mp/media/major-step-in-covid19-vaccine-rollout [Accessed 6 November 2021].

7. Australian Government Department of Health. COVID-19 vaccine rollout update - 5 November 2021. Canberra, ACT: DoH, 2021. Available at www.health.gov.au/resources/publications/ covid-19-vaccine-rollout-update-5-november-2021 [Accessed 6 November 2021].

8. Hunt G. TGA approval for Pfizer COVID-19 vaccine booster dose [Media release]. Canberra, ACT: DoH, 2021. Available at www.health.gov. $\mathrm{au} / \mathrm{ministers/the-hon-greg-hunt-mp/media/}$ tga-approval-for-pfizer-covid-19-vaccine-boosterdose-0 [Accessed 6 November 2021]. 